\title{
Phytochemical Constituents and Analgesic Activity of Ethyl Acetate Fraction of Punicagranatum L (Punicaceae)
}

\author{
Lamees A BenSaad* and Kah Hwi Kim \\ Department of Physiology, Faculty of Medicine, University of Malaya, Kuala Lumpur, 50603, Malaysia
}

*For correspondence: Email: Lameesbensaad@gmail.com; Tel: +603-79674923; Fax: +603-79674775

Received: 23 July 2014

Revised accepted: 29 November 2014

\begin{abstract}
Purpose: To investigate the active fraction of pomegranate fruit extract and screen it for analgesic activity.

Methods: The analgesic activity of pomegranate ethyl acetate fraction (EtOAc) was examined using three models of pain: writhing, hot tail flick and plantar tests. EtOAc was administered by oral gavage in doses of 100, 150 and $200 \mathrm{mg} / \mathrm{kg}$, p.o., for all the tests and compared to aspirin (100 mg/kg, p.o.) which was used as standard drug. Phytochemical studies of EtOAc were carried out by high performance liquid chromatography (HPLC) with ultraviolet (UV) detection and mass spectrometry (MS).

Results: In the writhing test, the index of pain inhibition (IPI) was $41 \%$ for EtOAc (200 mg/kg, p.o.) and $56 \%$ for aspirin. In the hot tail flick test, EtOAc (200 mg/kg, p.o.) showed analgesia reaching its peak at 60 min with maximum possible analgesia (MPA) of $30.5 \%$, compared with $43.8 \%$ for aspirin. Plantar test showed that pain was reduced by EtOAc in a dose-dependent manner and compared well with aspirin at $100 \mathrm{mg} / \mathrm{kg}$, p.o., dose. The $200 \mathrm{mg} / \mathrm{kg}$ dose showed the highest effect, prolonging withdrawal latency in the left hind paw to $11.9 \pm 0.3$ compared to aspirin with $13.4 \pm 0.2(p<0.001)$. HPLC analysis of EtOAc revealed the presence of gallic acid, ellagic acid and punicalagins $A \& B$. Confirmation of their structures was achieved by mass spectroscopy.

Conclusion: EtOAc has a central and peripheral analgesic effect that is most likely due to the presence of gallic acid and ellagic acid.
\end{abstract}

Keywords: Analgesia, Pomegranate, Gallic acid, Ellagic acid, Punicalagins, Phytochemical constituents

Tropical Journal of Pharmaceutical Research is indexed by Science Citation Index (SciSearch), Scopus, International Pharmaceutical Abstract, Chemical Abstracts, Embase, Index Copernicus, EBSCO, African Index Medicus, JournalSeek, Journal Citation Reports/Science Edition, Directory of Open Access Journals (DOAJ), African Journal Online, Bioline International, Open-J-Gate and Pharmacy Abstracts

\section{INTRODUCTION}

Punica granatum belongs to the Punicaceae family and is found in over 1000 cultivars [1]. It is cultivated in Iran, Afghanistan, India, Mediterranean countries and to some extent in the USA, China, Japan and Russia. The pomegranate plant is a large shrub or small tree, reaching a height of $20 \mathrm{ft}$ at maturity. It is more or less spiny and deciduous, with small, narrow oblong leaves and short stems. The pomegranate fruit is berry-like with a leathery rind enclosing many seeds surrounded by juicy arils [2]. Pomegranate fruit is very rich in antioxidants [3] and contains bio-active compounds which aid in good health [4]. Among the antioxidants, punicalagin and ellagic acid have been identified [4]. Punicalagins possess two isomeric forms in pomegranate: $\alpha$ and $\beta$. Punicalagin is an ellagitanin in which the gallagic acid and ellagic acid are linked through a molecule of glucose [5]. Punicalagin could inhibit proliferation of human tumor cells (oral, colon or prostate) [6]. Punicalagins and ellagic acid are also responsible for the antioxidant activity and healthy benefits of pomegranates [7]. Ellagic acid 
shows health benefits against cancer, cardiovascular diseases and other diseases [8]. Punicalagins inhibit proliferation of human tumor cells (oral, colon or prostate) [6]. Gallic acid possesses several biological activities, including antioxidant, anti-tyrosinase, antimicrobial and anti-inflammatory activities [9].

In our previous work, we have affirmed that the crude ethanol extract was able to produce significant analgesic effect [10]. The present study was undertaken to provide further pharmacological insight into the active fraction, and the mechanisms of analgesic activity.

\section{EXPERIMENTAL}

\section{Plant material}

Pomegranate fruits were collected from Tripoli, Libya in the fall of 2010 . The plant material was identified and authenticated taxonomically at Tripoli-University Herbarium by Dr. Al-Sheriff (Department of Botany, Tripoli-University). A voucher specimen (01563) was deposited at the same herbarium for future reference. Fruits were transferred to $4{ }^{\circ} \mathrm{C}$ store room on the harvest day.

\section{Animals}

Albino mice (20 - $30 \mathrm{~g}$ ) and Sprague Dawley rats $(180-200 \mathrm{~g})$ of either sex were used in this study. The animals were procured from the animal unit of Faculty of Medicine Animals were housed at a temperature of $24 \pm 2{ }^{\circ} \mathrm{C}$ and relative humidity of $30-70 \%$. A 12:12 light: dark cycle was followed. All experiments were carried out in strict compliance with the ethical guidelines for investigation of experimental pain in conscious animals [11], after obtaining approval from the animal ethics committee of University of Malaya (Ethic number: FIS/27/01/ 2012/LAB (R)).

\section{Extraction method}

Pomegranate extract and its fractions were prepared with references to methods of [10]. The whole fruits were cleaned, freeze-dried and grounded into powder using a blender. Then the powder was dried in an oven at $40{ }^{\circ} \mathrm{C}$ for $24 \mathrm{~h}$. The powder was sieved through a 24-mesh filter. The resultant powder of one kilogram was extracted with $2500 \mathrm{ml}$ of $80 \%$ ethanol in water at room temperature for $24 \mathrm{~h}$ in a shaking water bath and then was filtered. The ethanol was removed by using RV10 rotary evaporator (IKA, Guangzhou,China) and the resultant residue was crude ethanolic extract (EPE, yield $11 \%$ ).
Approximately $100 \mathrm{~g}$ of crude ethanol extract was mixed with $200 \mathrm{ml}$ of $\mathrm{n}$-hexane to dissolve the non-polar compounds. The mixture was filtered and the filtrate was concentrated by the rotary evaporator yielding the hexane fraction. The hexane insoluble residue was subjected to partitioning between the ethyl acetate and distilled water (immiscible solvents) using a separating funnel. The ethyl acetate was removed using rotary evaporator and the water was removed by a freeze dryer to give the ethyl acetate fraction (EtOAc) and the water fraction. The yield of the ethyl acetate fraction was $3.5 \%$. Both the crude ethanolic extract EPE and EtOAc were stored in air tight containers in the dark until further use.

HPLC analysis with UV detection and structure confirmation by mass spectrometry

The sample was prepared and run on Beckman System Gold HPLC with UV- detection to monitor gallic acid, ellagic acid and punicaligin elution. Standards were used to establish the retention time of the compounds of interest. The sample and standards were separated on a $15 \mathrm{~cm} \times 4.6$ $\mathrm{mm}, 3 \mu \mathrm{m}$ SUPELCO, Supelcosil LC-18-T (58970-U) and HPLC column by employing the following method: Mobile Phase A: $0.1 \%$ Phosphoric Acid in water (buffer system), Mobile Phase B: $100 \%$ Acetonitrile with the following gradient: 0-20 min, $0 \%$ B; 20 - $25 \mathrm{~min}, 50 \% \mathrm{~B}$; $25-45 \mathrm{~min}, 0 \% \mathrm{~B}$ with a flow rate of $0.5 \mathrm{ml} / \mathrm{min}$, and UV detection monitored at 220, 246, $280 \mathrm{~nm}$. The identification of each compound was made by comparing the retention times, UV spectra and high resolution mass spectra with those corresponding to standards. Gallic Acid ( $\mathrm{TCl}$, Portland, OR; \#G0011): $50 \mu \mathrm{g} / \mu \mathrm{l}$ stock made up in $\mathrm{MeOH}$

Ellagic acid (Indofine, Hillsborough, NJ; \#E-001): $0.604 \mu \mathrm{g} / \mu \mathrm{l}$ stock made up in $\mathrm{MeOH}$. Punicalagin (Sigma, St Louis, MO; \#P0023): $5 \mu \mathrm{g} / \mu \mathrm{l}$ stock made up in $\mathrm{MeOH}$, Sample (9.38 mg), was dissolved in (98 $\mu \mathrm{L}$ DMSO) to give a final concentration of $100 \mu \mathrm{g} / \mu \mathrm{L}$. $500 \mu \mathrm{g}$ of sample was loaded and the fractions were collected. The fractions matching the retention time of the standards were checked by direct infusion into a LTQ-Velos Orbitrap Pro using an Advion Triversa nano spray robot after cleanup of a small portion using C18 zip-tips (to desalt). HPLC traces and mass spectra are attached. Mass error relative to theoretical is indicated in the spectra.

\section{Acetic acid writhing test}

Mice were divided into five groups of six mice each and pretreated with (saline), aspirin (100 
$\mathrm{mg} / \mathrm{kg}$, p.o.), and EtOAc (100, 150 and 200 $\mathrm{mg} / \mathrm{kg}$, p.o.) $30 \mathrm{~min}$ before injection of acetic acid $(0.6 \mathrm{v} / \mathrm{v})$ i.p. The number of abdominal constrictions (full extension of both hind paws) produced in each group was counted for $30 \mathrm{~min}$ and compared to the response in the control group. The antinociceptive activity was expressed as percentage of inhibition of the abdominal constrictions [12].

\section{Hot tail flick test}

Mice were divided into five groups of six mice. The lower part of each tail was immersed in a beaker of water maintained at a temperature of $55 \pm 0.5{ }^{\circ} \mathrm{C}$. The reaction time was the time for the tail to be withdrawn from water with a cut-off time set at $10 \mathrm{~s}$. The reaction time was measured at $15,30,45,60 \mathrm{~min}$ after oral (by gavage) administration of EtOAc $(100,150,200 \mathrm{mg} / \mathrm{kg}$, p.o.) or aspirin (100 mg/kg, p.o.) [13].

\section{Plantar test}

The Hargreaves' test was performed using a standard apparatus (Ugo Basile). The test consisted of placing a rat in a transparent acrylic box and a mobile infrared heat lamp was placed underneath the hind paw to be tested. The latency of the paw withdrawal response was measured automatically with the help of a photoelectric-sensitive device after the thermal radiant stimulus was applied to the plantar surface. The latency of the withdrawal response of each hind paw was determined at $30,60,90$, $120,150,180,210,240,300$ min post-challenge, with the left paw being stimulated with the carrageenan and the right one stimulated with sterile saline. EtOAc (100, 150, $200 \mathrm{mg} / \mathrm{kg}$, p.o.) and aspirin (100 mg/kg, p.o.) was administered by oral gavage $30 \mathrm{~min}$ before the subcutaneous injection of both rat hind paws [14].

\section{Statistical analysis}

Data were represented as mean \pm standard error of the mean (SEM). The results were analyzed using one way analysis of variance (ANOVA) for comparison between groups followed by students't-test.

\section{RESULTS}

\section{Phytochemical profile}

HPLC analysis showed the presence of gallic acid $(50.3 \mathrm{mg} / \mathrm{kg})$, ellagic acid $(81.7 \mathrm{mg} / \mathrm{kg})$ and punicalagins A \& B $(4.98 \mathrm{mg} / \mathrm{kg})$ (Figure 1). The mass spectra of gallic acid and ellagic acid are shown in Figures 2 and 3.

\section{Writhing}

EtOAC at doses $(100,150,200 \mathrm{mg} / \mathrm{kg}$, p.o.) reduced pain response in a dose dependent manner when compared to control group aspirin $(100 \mathrm{mg} / \mathrm{kg}$, p.o.), the standard drug significantly reduced the number of writhing. The index of pain inhibition (IPI) induced by the ethanol pomegranate extract at all doses was 24, 31 and $41 \%$, respectively, while aspirin produced IPI of $56 \%$ (Figure 4A)

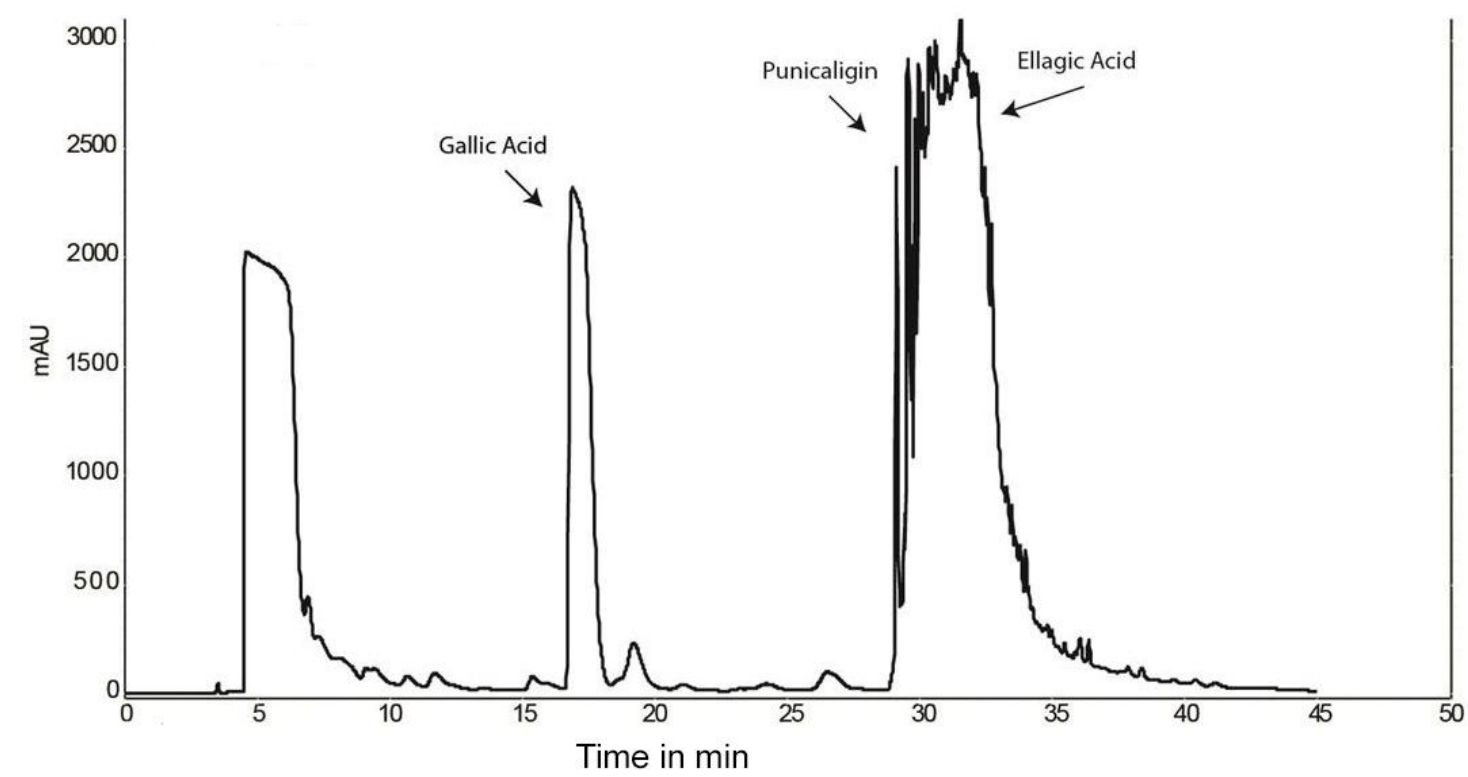

Figure 1: High performance liquid chromatogram of EtOAc. Peaks indicate gallic acid, punicaligin and ellagic acid 
Pomegranate_EtOAcExtractFxn-35\#7RTg.1AV: 1NL: 9.85E5 TFTMS-cNISFullms [150.00-600.00]

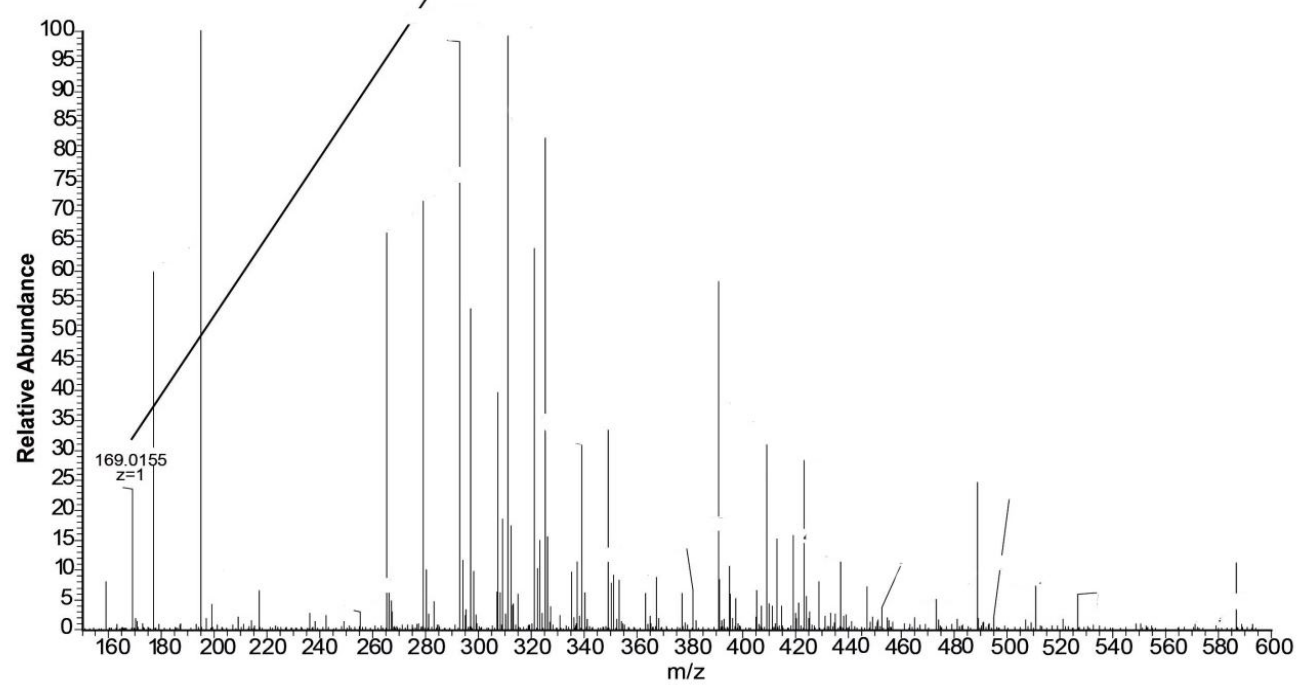

Figure 2: Mass spectrum of EtOAc showing the presence of gallic acid ([M-H]-m/z 169)

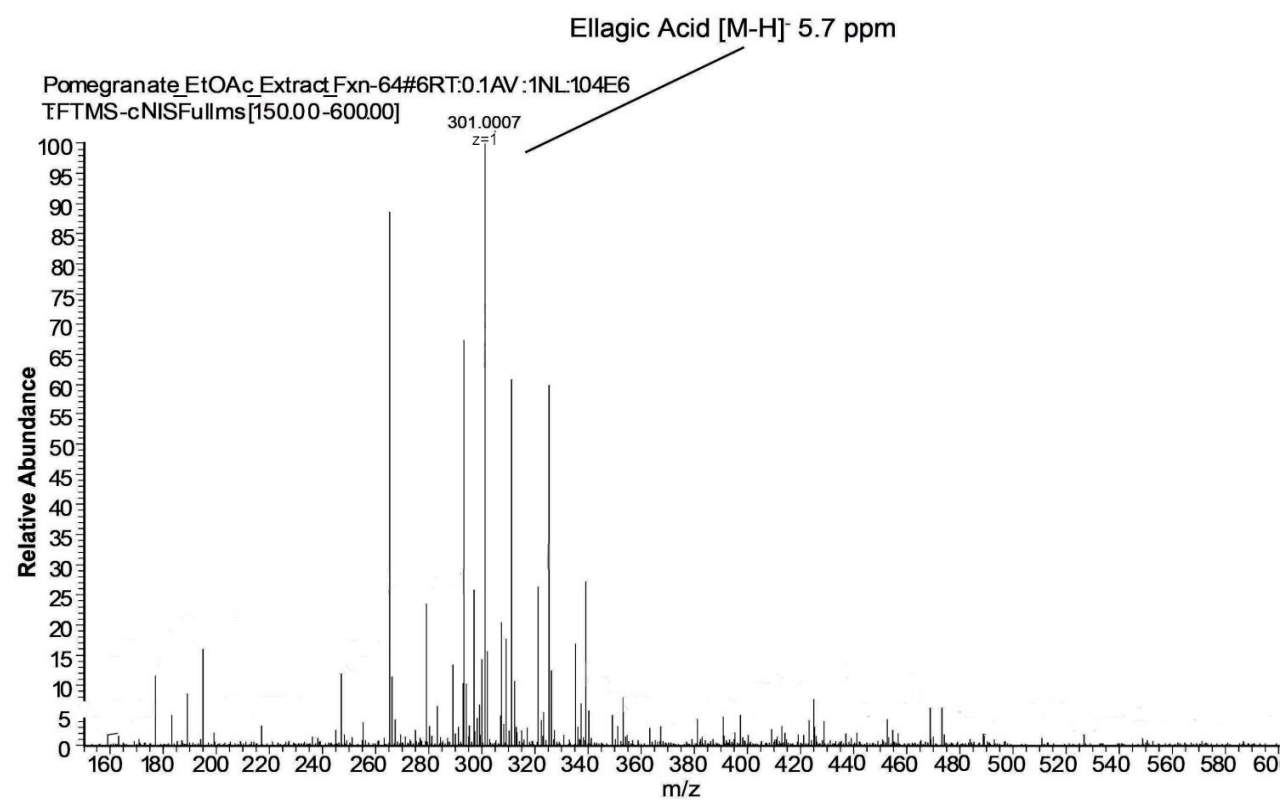

Figure 3: Mass spectrum of EtOAc showing the presence of ellagic acid $([\mathrm{M}-\mathrm{H}]-\mathrm{m} / \mathrm{z} 301)$

\section{Hot tail flick}

The hot tail flick test results showed that MPA (maximum possible analgesia) increased in a dose-related manner, reaching a peak at $60 \mathrm{~min}$ for all doses, i.e., $12.3,20.6$ and $30.5 \%$ at 100 , 150 and $200 \mathrm{mg} / \mathrm{kg}$, respectively, and $43.8 \%$ for aspirin (Figure 4B).

\section{Peripheral anti-nociceptive action on right} hind paw injected with carrageenan

For the control group (carrageenan) withdrawal latencies were shortened from $10.0 \pm 0.2$ to $5.6 \pm$
0.2 indicating (hyperalgesia) and for the EtOAc $(100,150$ and $200 \mathrm{mg} / \mathrm{kg})$, carrageenan induced hyperalgesia was reduced. The anti-nociceptive effect was exhibited in a dose dependent manner where $200 \mathrm{mg} / \mathrm{kg}$ showed significant response which was comparable to aspirin, the significant effect started at $90 \mathrm{~min}(p<0.05)$ and remained constant throughout the observation period of 5 hours. The highest effect withdrawal latency prolonged to $13.4 \pm 0.3(p<0.001)$ compared to aspirin $13.7 \pm 0.2(p<0.001)$ Figure $5 \mathrm{~A}$. 
Central anti-nociceptive action on right hind paw injected with saline

Latencies were shortened from $10.5 \pm 0.2$ to 5.8 \pm 0.2 for the control group (saline) and for the ethyl acetate fraction of pomegranate $(100,150$ and $200 \mathrm{mg} / \mathrm{kg}$ ). Algesia was reduced and antinociceptive effect was exhibited in a dose

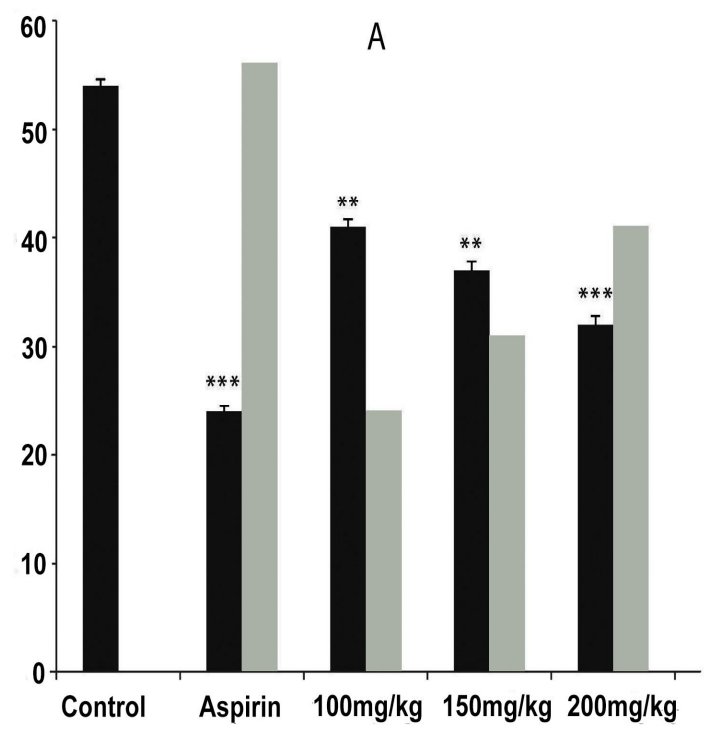

dependent manner. Significant analgesia was observed at $90 \min (p<0.01)$ and remained constant throughout observation period of 5 hours this significant effect was comparable to aspirin At $200 \mathrm{mg} / \mathrm{kg}$ withdrawal latency prolonged to $11.9 \pm 0.3(p<0.001)$ compared to aspirin $13.4 \pm 0.2(p<0.001)$ Figure 5B.

\section{B}

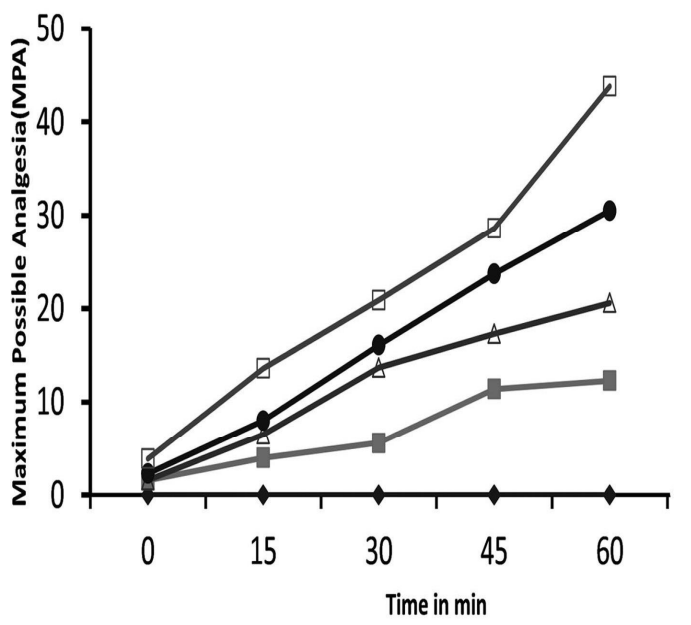

Figure 4: (A) Effect of EtOAc (100, 150 and $200 \mathrm{mg} / \mathrm{kg}$, p.o.) and aspirin (100 mg/kg, p.o.) on writhing of mice. IPI: index of pain inhibition. Key: Number of writhes (Ш), IPI(Ш); (B) Effect of $\mathrm{mg} / \mathrm{kg}(\boldsymbol{\bullet}), 150 \mathrm{mg} / \mathrm{kg}(\Delta)$, $200 \mathrm{mg} / \mathrm{kg}(\bullet)$, aspirin(口). Data are expressed as mean \pm SEM $(n=6)$. The differences between groups were statistically analysed by ANOVA followed by t- test; ${ }^{* *} p<0.01,{ }^{* * *} p<0.001$ vs control (saline)
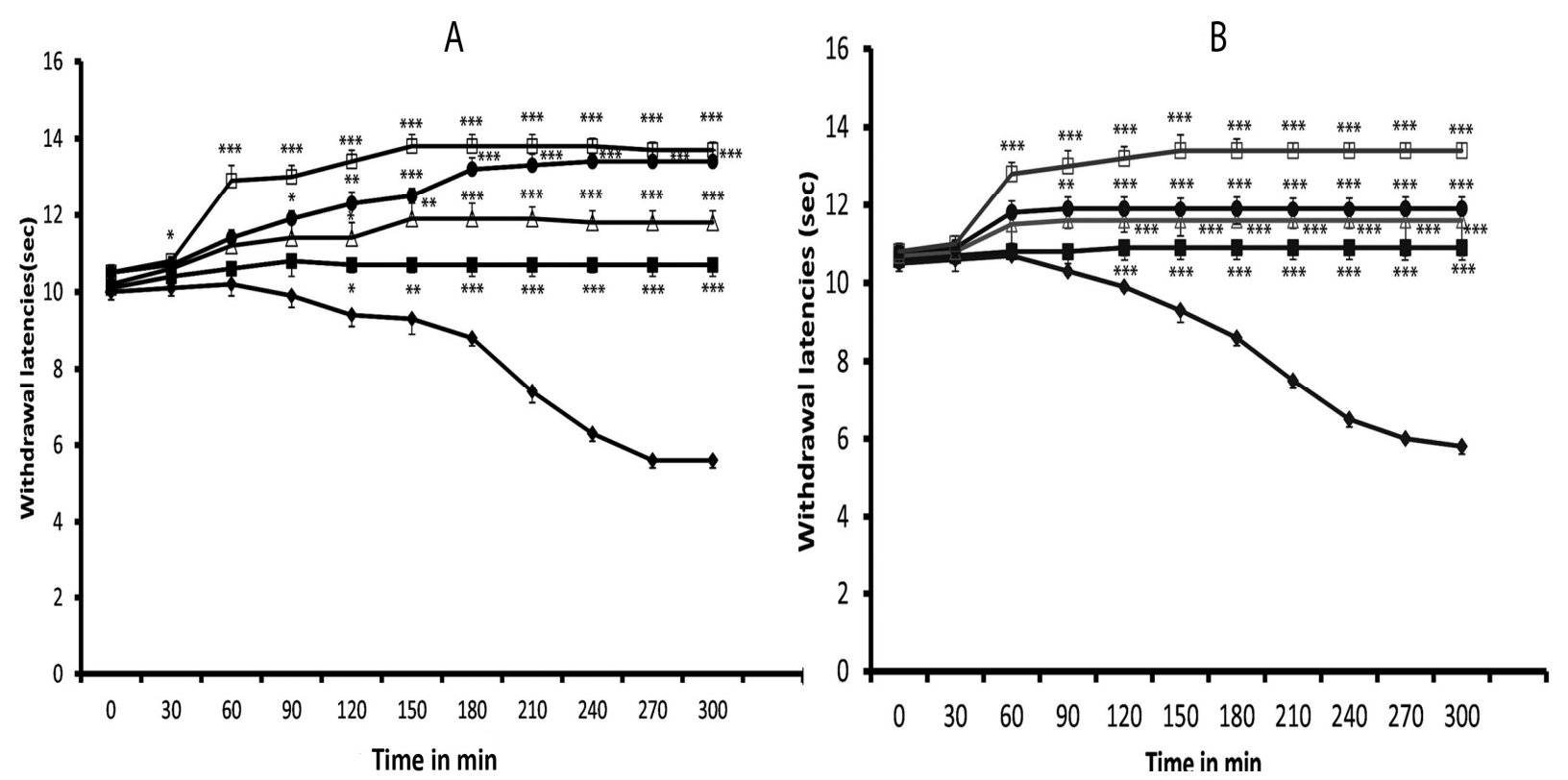

Figure 5: (A) Effect EtOAc (100, 150, $200 \mathrm{mg} / \mathrm{kg}$, p.o.) on withdrawal latencies and aspirin (100 mg/kg, p.o.) vs control (carrageenan) on right hind paw in plantar test; (B) Effect of EtOAc $(100,150,200 \mathrm{mg} / \mathrm{kg}$, p.o.) on withdrawal latencies and aspirin (100mg/kg, p.o.) vs control (saline) on left hind paw in plantar test; Key: Saline $(\triangleleft), 100 \mathrm{mg} / \mathrm{kg} \mathrm{( \bullet ),} 150 \mathrm{mg} / \mathrm{kg}(\Delta), 200 \mathrm{mg} / \mathrm{kg} \mathrm{( \bullet )}$, aspirin ( $\square)$; data are expressed as mean \pm SEM $(\mathrm{n}=6) ;{ }^{*} p<$ $0.05,{ }^{* *} p<0.01,{ }^{* * *} p<0.001$ vs control 


\section{DISCUSSION}

In the present study, we performed a phytochemical analysis, investigated EtOAc analgesic properties and tried to elucidate EtOAc mechanism of action.

The acetic-acid-induced abdominal constriction test is a well-known model for inflammatory pain and has been used to screen for analgesic or anti-inflammatory properties of new agents [12]. In addition, it is frequently used as a model to study the peripheral anti-nociceptive effect of extracts [15]. This model of nociception is well known to represent the stimulation of peripheral mechanism since the administration of phlogogen lead to an increase in the levels of cyclooxygenase (COX) and lipooxygenase (LOX) [16]. The ability of EtOAc to attenuate aceticacid-induced abdominal constriction suggests that anti-nociceptive mechanism may involve the inhibition of COX and LOX in the peripheral tissues leading to a decrease in PGEs synthesis and impediment of the pain transduction in primary afferent nociceptor.

The hot tail flick test is usually used in conjunction with the writhing test to distinguish central nervous system effects from peripheral ones. Our results indicated that EtOAc significantly prolonged the time that mice could endure heat stimuli in a dose dependent manner. Similar findings were reported by Parminder [17]. The Hargreaves model (1988) is actually a suitable model in determining the antiinflammatory effect and its mechanism of action either acting on COX-1 or COX-2 and via either the peripheral or CNS response [18]. This model is also a sequel to carrageenan-induced oedema model. Thus, rat's hind paw injected with carrageenan can be used to evaluate both antiinflammatory and anti-nociceptive effects.

EtOAc given orally produced a dose-dependent significant suppression on pain induced by the radiant heat applied to the plantar surface of the heel of the right hind paw injected with carrageenan (Figure 5A) and left hind paw injected with saline (Figure 5B).

Ellagic acid has been reported to possess both peripheral and central anti-nociceptive activities when tested by writhing test and hot tail flick test $[19,20]$. Some studies have confirmed the antinociceptive effects of gallic acid in models of acute pain such as the acetic acid writhing test and cyclophosphamide-elicited cystitis [9,21]. In addition gallic acid has also demonstrated to possess anti-nociceptive property when studied on a neuropathic pain model [7].

According to the previous reports, ellagic acid and gallic acid exhibit analgesic potential through peripheral and central mechanisms [19-21,7]. EtOAc showed analgesic potential through both peripheral and central components. Therefore, it is suggested that ellagic acid and gallic acid present in EtOAc fruit extract may be the compounds responsible for its analgesic effect.

An important limitation of this study is that despite the successful isolation of both ellagic acid and gallic acid, they have not been tested for their relative analgesic activity. This was due to lack of funds at the time of study. However, this limitation has been expanded in our progressing studies which are examining the possible mechanism of action of pure isolates of both ellagic acid and gallic acid.

\section{CONCLUSION}

The findings of this study demonstrate that EtOAc exhibits significant analgesic activity, possibly, via central and peripheral mechanisms. Ongoing studies in our laboratory will further confirm whether ellagic acid and/or gallic acid are responsible for its analgesic actions.

\section{ACKNOWLEDGEMENT}

The authors would like to thank the University of Malaya for supporting this research through a postgraduate research grant (PV151/2012A) and UMRG 356/11HTM.

\section{REFERENCES}

1. Levin GM. Pomegranate (Punica granatum) plant genetic resources in Turkmenistan. Plant Genetic Resour Newsl. 1994; 97: 31-37.

2. Fawole OA, Opara UL. Developmental changes in maturity indices of pomegranate fruit: $A$ descriptive review. Scienta Horticulture. 2013;159: 152-161

3. Calin Sanchez A, Martinez J, Vazquez A, L-BurloFMelgarejo $P$, Carbonell BAA. Volatile composition and sensory quality of Spanish pomegranates (Punica granatum L.). J Sci Food Agric. 2010; 91: 586-592

4. Calin Sanchez A, Carbonell BAA. The pomegranate fruit grown in Spain Antioxidant punicalagin in pomegranate juice and pomegranate extract, for functional diet of the future vyd.Granatum Plus: Miguel Hernandez University, Food Technology department 2012.79p 
5. Cerada B, Llorach R, Ceron JJ, Espin JC, Tomas Barberan FA. Evaluation of the bioavailability and metabol ism in the rat of punicalagin, an antioxidant polyphenol from pomegranate juice. Eur $J$ Nutr. 2003; 42: 18-28

6. Jemal A, Bray F, Center MM, Ferlay J, Ward E, Forman D. Global cancer Statistics. CA Cancer J Clin. 2011; 61: 69-90.

7. Taygi S, Singh A, Bhardwaj $P$, Sahu S, Yadav $P$, Kori ML. Punicalgins-A Large Polypheno Compounds Found in Pomegranates: A Therapeutic Review. J Plant Sci. 2012; 5(2): 45-49

8. Sun J, Chu YF, Wu X, Liu RH. Antioxidant and antiproliferative activities of common fruits. J Agri Food Chem. 2002; 50 (23): 9559-9570.

9. Krough $R$, Yunes $R A$, Andricpulo $A D$. Structure activity relationship for the analgesic activity of gallic acid derivatives II. Farmaco. 2000; 55: 730-735

10. BenSaad LB, Hwi KK, Quah T. Evaluation of the antinociceptive effect of the ethanolic extract of Punica granatum. Afr J Tradit Complement and Altern Med. 2014; 11(3): 228-233

11. Zimmermann M. Ethical guidelines for investigations of experimental pain in conscious animals. Pain. 1983; 109-110

12. Collier HO, Dinneen LC, Johnson CA, Schneider C. The abdominal constriction response and its suppression by analgesic drugs in the mouse. Br J Pharmacol. 1968; 32 (2): 295-310

13. Sewell RDE, Spencer PSJ. Antinociceptive activity of narcotic agonist and partial analgesics and other agents in the tail immersion test in mice and rats. Neuropharmacol. 1976; 15: 23-29

14. Hargreaves $K$, Dubner $R$, Brown F, Flores C, Joris J. A new and sensitive method for measuring thermal nociception in cutaneous hyperalgesia. Pain. 1988; 32(1): 77-88

15. Bhukya B, Reddy RN, William CM, Gottumukkala KM. Analgesic and antinflammatory activities of leaf extract of Kydia calycina Roxb. Bangladesh J Pharmacol. 2009; 4: 101-104

16. Ikeda Y, UenoA, Naraba H, Oh-Ishi S. Involvement of vanilloid receptor VR1 and prostanoids in the acidinduced writhing responses of mice. Life Sciences. 2001; 69 (24): 2911-2919.

17. Pariminder N, Mamta S, Manisha M. Evaluation of Antiinflammatory and Analgesic activity of Punica granatum Linn leaves. International Journal of Research in Ayurveda \&Pharmacy. 2011; 2(3): 987990

18. Yaksh $T L$, Dirig DM, Conway CM, Svensson C, Luo ZD, Isakson PC. The acute antihyperalgesic action of nonsteroidal anti-inflammatory drugs and release of spinal prostaglandin E2 is mediated by the inhibition of constitutive spinal cyclooxygenase-2 (COX-2) but not COX-1. J Neurosci. 2001; 21(16): 5847-5853

19. Mansouri MT, Naghizadeh B, Ghorbanzadeh. Involvement of opiod receptors in the systemic and peripheral antinociceptive actions of ellagic acid in the rat formalin test. Pharmacol Biochem Behav. 2014; 120: 43-49

20. Mansouri MT, Naghizadeh B, Ghorbanzadeh B, Farbood Y. Central and Peripheral antinociceptive effects of ellagic acid in different models of pain. Eur $J$ Pharmacol. 2013; 707(1): 46-53

21. Krough $R$, Yunes RA, Andricpulo AD. Structure activity relationship for the analgesic activity of gallic acid derivatives II. Farmaco. 2000; 55: 730-735 